https://doi.org/10.48009/1_iis_2007_217-223

\title{
THE ADOPTION OF SYNCHRONOUS AND ASYNCHRONOUS MEDIA IN THE TEACHING OF A SECOND LANGUAGE
}

\author{
Yen-Tzu Chen, Nova Southeastern University, yentzu@nova.edu \\ Che-Hung Liu, Florida International University, cliu001@fiu.edu \\ Roman Wong, Barry University, rwong@mail.barry.edu
}

\begin{abstract}
This paper discusses the use of synchronous and asynchronous media methods in the field of second language learning, its advantages, and challenges. We, based on Krashen's second language acquisition theories, formulated an evaluation framework for identifying asynchronous and synchronous media methods to be used in different language instruction scenarios.
\end{abstract}

Keywords: Online Learning, Asynchronous Media, Synchronous Media, Second Language Acquisition

\section{INTRODUCTION}

Information and communication technology (ICT) can be a powerful vehicle that allows course instruction to be delivered to more people located in geographically dispersed places. Automation and computer mediated learning have made educational opportunities more available and affordable. Prior research has found that computer-aided instruction has a positive effect on students' learning [1, 2, 3]. The sophisticated functionality coming with most computer-aided instruction has become an increasingly helpful learning tool to address the very specific needs of individual learners. More recently, computer-aided instruction has become increasingly popular in the field of second language education. For instance, Warschauer [28] observes that English as Second Language (ESL) students in Hawaii using a real-time computer-assisted conversation function to gain additional writing practice in class. The written interaction enhances students' participation and collaboration. Additionally, the email discussion groups provide chances for students to learn how to conduct research on the Web. The key differences between computer-aided instruction and traditional face-to-face class are time dependence, place dependence, the structure of communication and richness of communication [30].

It is believed that integrated information and communication technologies, such as computer-assisted language learning (CALL) and computer-mediated communication (CMC), are the keys to enriching language teaching; by applying these technologies, educators can take advantages of the many functions computers providing to enhance classroom activities and lectures $[4,5]$. Both CALL and CMC environments can be applied in synchronous and asynchronous systems, which have been widely used in distance learning courses [29].

An asynchronous system is one in which learners can work at their own places and preferred times [6], such as e-mail or online confererencing systems. The most important aspect is that all learners are not present at the same time or in the same place as other learners with whom they are communicating or from whom they are learning, although they are online at the same time by chance or plan. Simpson's 2006 study described a typical asynchronous system in use: 160 graduate students took an online course through asynchronous system. Some used the system in the computer lab while others preferred working from home to communicate or respond the messages [7].

Meanwhile, synchronous system is that which occurs at the same time for all learners but at different places thanks to the Internet; synchronous systems include text chats and video conferencing [6]. Pelowski et al.'s study involved a typical synchronous system; 26 students enrolled in an online introductory psychology class participated in 12 text chat sessions that required them to communicate with others who were also online at the time, but the students accessed the system from various places [8].

The goal of this study is to investigate how language instructors can use synchronous and asynchronous ICT as a media to enrich their second language lessons in a meaningful and effective manner. The following discussion will introduce how synchronous and asynchronous media have already been used in the field of second language learning, and what specific questions educators must overcome in applying synchronous and asynchronous media to the second language learning environment. Additionally, we will demonstrate the synchronous and asynchronous media in second language environment, Krashen's second language acquisition theory [9], and the evaluations to adopt synchronous and asynchronous media in the second language learning environment. This study 
ends with contribution and conclusion.

\section{COMPUTER MEDIATED LEARNING OF A SECOND LANGUAGE}

The ICTs used in computer mediated instruction of second languages can be classified into either synchronous or asynchronous. Synchronous media methods are time-bound that both of the instructor and learners would need to be attending the session simultaneously. Asynchronous media methods, on the other hand, do not require the participants to attend the instruction session at the same time. This is achieved by having the whole structure of instruction materials preloaded on a computer-based repository accessible by the participants. The following paragraphs provide a summary of the relevant findings from prior studies relating to the use of the two kinds of computer mediated learning methods.

\section{Synchronous Methods of Computer Mediated Instruction}

Groupware applications are generally incorporated with a functionality that can provide good functional and interactive support for second-language instruction. Hampel [4] found that face-to-face teaching can be transferred to a synchronous media application with a rich set of groupware functions. For example, an application package called Lyceum, which is designed to enhance synchronous interactions with learners using audio, writing, and graphics. The groupware functions available in Lyceum for manipulating text and image information among participants enable learners to easily work together in small groups. However, the limited media richness of this kind of application software does not allow the students to effectively discern other learners' behaviors through observing each others' 'body language', which is otherwise available in a face-to-face classroom scenario [4].

Videoconferencing is another synchronous media method providing strong interactive capability, yet a high level of media richness, in group support. It addresses the issue of lacking "body language" in groupware. In the one-to-one situations, videoconferencing environment is similar to the traditional face-to-face classroom setting [5]. For example, NetMeeting, an Internet-based desktop videoconferencing tool with a strong video and audio functionality allows geographically distributed learners and instructors to see and hear each other [5]. Unlike other online multi-way group support technologies, videoconferencing enables instructors and researchers to know more about the special needs of the learners by actually 'seeing' each other. Thus, a videoconferencing mediated environment can be much more information intensive. The effect of high information intensity can be moderated by the linguistic level of learners. While the more advanced learners can be benefit by the enriched learning environment, the more elementary level learners, may have to struggle more to understand the non-textual information conveyed in a spoken form. Due to the learners' restricted vocabulary and low listening capability, the instructor frequently needs to either explain a concept in the target language in several ways or even explain it using the learners' native language. In addition, the instructor many times has to repeat the information numerous times and in a slower pace [5]. Jepson [10] in analyzing the learning effect in the synchronous non-native speaker (NNS) text and voice chat rooms has arrived at a similar conclusion. He found that the voice chats had a higher number of total repair moves than the text chats. He concluded that the text chat rooms benefit learners who do not live in a target language-speaking area. The use of the voice chats can only used to support and enrich second language development.

Other problems experienced by the participants when a rich media synchronous method is used is that the participants' awareness of their exposure to a camera or video recorder may cause them to feel unnatural. Such an unnatural feeling may serve as a nuisance to distract the learners from the instruction. Furthermore, the various technical functions of the application packages may cause both the instructor and the learners to feel under pressure and distracted. A 2004 study conducted by Ware found that learners' technological abilities affect their performances in learned a second language using synchronous media. In addition to their technical skills, learners' typing capability also has an impact on their learning. It is noticed that the slower typing speeds of learners impede their ability to keep up with and understand the discussions in a text chat room. Often these learners feel as though they are outsiders eavesdropping in on a text conversation [11]. In such situations, instructors must be able to control the text chat room when learners are at the beginning levels by using limited language to chat with learners.

Another factor that has an impact on the instruction environment is that the quality of the transmitted video and audio information is very much dependent upon how much bandwidth is available and the network traffic conditions. Low speed channels or a heavy network traffic can cause the streaming of the information to be disrupted and hard to be interpreted or understood [5]. 
In addition, educators must consider students' various cultural backgrounds [12]. Synchronous media give language learners more opportunities to practice authentic language, but before applying the media the instructors have to consider how learners adapt to such environments and their experience and ability to use the technology.

\section{Asynchronous Methods of Computer Mediated Instruction}

Unlike synchronous media environments, participants are more independent and have more freedom in choosing when to participate in an instruction session. In terms of the technical requirements (such as the needs for more equipment), asynchronous methods are more accessible compared to synchronous methods. The major problem of asynchronous media instruction methods is its lack of interactivity among the instructors and learners. This can, however, be an advantage for the elementary level learners who can spend longer time in helping themselves to the instruction materials.

Bulletin boards and email are the most commonly used asynchronous media tools [13]. However, Pan and Sullivan [14] pointed out that learners often feel isolated when using asynchronous media such as message postings, and many online learners do not check their email often, thereby limiting their access to potential learning. As a result, in using such tools, instructors must not only consider learners' potential feelings of isolation, but also provide a framework to facilitate students' learning activities. For example, the instructors may need to periodically remind language learners to check their email boxes regularly, encourage them to use email to send opinions and ask questions, and provide discussion forum to make learners practice with their writing skills when communicating among instructors and other learners. According to Ware [11], such discussion board tools can help language learners improve their syntactic complexity while they compare their writing styles and skills with their peers'.

Jiang and Ramsay [15] used a different yet innovative asynchronous tool in their study: the sound file. In this research, sound-file questions were posted on the WebCT discussion board each week throughout the semester. Language learners recorded their answers to these questions on the sound files. Both of the learners and instructors found the communication using the sound files to be enjoyable and useful.

Arnold and Ducate [16] encourage future language instructors to become more familiar with technology through Asynchronous Computer-Mediated Communication (ACMC); the fulfillment of ACMC conducts learners to enjoy the interactive online discussions as a social and cognitive presence in deep processing. Zeiss and Isabelli-García [17] also demonstrate that ACMC can not only help learners understand the culture of the target language more deeply, but also encourage learners to pursue additional study, including study abroad.

By integrating a set of learning materials on CD-ROMs through course-management systems (CMS) packages like WebCT and Blackboard [18], asynchronous media is becoming more interactive and flexible for use in a language course. The utilization of CD-ROMs can help learners reduce stress and enhance their self-instruction and self-confidence through game and communicative activities. Learner's learning processes can be analyzed and recorded in the data, enabling instructors to support learners' specific needs in a meaningful way [19]. Meanwhile, learners get information about the target language from the CD-ROMs and use the CMS tools to communicate or discuss issues with both instructors and peers. Although many language instructors and researchers are trying to apply CMS in language courses, Learning Management Systems (LMS) is not specifically designed for language learning [18]. In addition, lower level learners tend not to use CD-ROMs effectively, often choosing to focus only on audio and textual options; meanwhile learners at the more advanced levels preferred audio practice [20].

\section{KRASHEN'S THEORIES OF SECOND LANGUAGE ACQUISITION}

According to Krashen, the effective learning of a second language requires not an extensive use of conscious grammatical rules but a lot of natural and meaningful interactions with sympathetic native speakers [9, 31]. His theories can be manifested in the following five hypotheses [22]:

Acquisition-learning hypothesis. Krashen defined the first component, acquisition, as a natural language process in which meaningful interactions with native speakers using the target language without focusing on its form. This process is similar to first language acquisition [9, 22]. The second component, learning, which involves the learners' learning about the language, such as the use of the grammatical rules. Compared to the acquisition component, the learning component is less important. Krashen suggested teaching a language should focus on communication, not forcing learners to learn by rote rules [23]. 
Monitor hypothesis. The monitor hypothesis explains the relationship between acquisition and learning and defines the influence of the latter on the former, as such, this hypothesis is in close association with the learning component of his acquisition-learning hypotheses. In that the learning component functions to help the person to filter his/her language. The person applies his/her learning of the grammatical rules to plan, monitor and correct the language outcomes of an interactive or writing communication. The monitoring function is the practical result of the learned grammar. The monitoring function, however, works on three conditions: (a) the second language learner has sufficient time at his/her disposal, (b) he/she focuses on form or thinks about correctness, and (c) he/she knows the rule.

Natural order hypothesis. The natural order hypothesis states that students acquire (not learn) grammatical structures in a predictable order with certain items being learned before others [32]. This order appears to be independent of the learner's age, conditions of exposure, and the background of the native language development. Although natural order patterns of second language (L2) acquisition do not follow those of the first language acquisition patterns, there are patterns to second language development. Both children and adults seem to follow the same pattern [32].

Input hypothesis. Krashen's input hypothesis was built on Vygotsky's zone of proximal development. Both emphasize that language acquisition is achieved through human social interaction-communication [25]. According to this hypothesis, the learner improves and progresses along the 'natural order' when he/she receives second language 'input' that is one step beyond his/her current stage of linguistic competence [22]. That is, if a learner's linguistic level is at stage I; then acquisition takes place when he/she is exposed to 'Comprehensible Input' that belongs to level i+1. Since not all of the learners can be at the same level of linguistic competence at the same time, therefore, natural communicative input is the key to designing a syllabus to ensure the learners to have an appropriate level of input.

Affective filter hypothesis. The affective filter hypothesis states that second language acquisition is affected by social-emotional variables. According to Krashen, learners learn best when two conditions are met: learning takes place in a low-anxiety environment, and learners have the motivation and self-confidence to learn [9]. According to this hypothesis, learners with high motivation, self-confidence, a good self-image, and a low level of anxiety show a higher level of second language acquisition. On the other hand, learners with a low motivation, low self-esteem, and debilitating anxiety can combine to 'raise' the affective filter and form a 'mental block' that prevents comprehensible input from being used for acquisition.

\section{THE ADOPTING SYNCHRONOUS AND ASYNCHRONOUS MEDIA IN THE SECOND LANGUAGE LEARNING ENVIRONMENT}

Based on Krashen's five hypotheses of second language acquisition theory, we present a framework to evaluate both synchronous and asynchronous media in the second language learning environment (as Table 1).

\begin{tabular}{|c|c|}
\hline \multicolumn{2}{|c|}{$\begin{array}{c}\text { Table 1 } \\
\text { An Evaluation Framework for Selecting } \\
\text { Media Tools for Second Language Instruction }\end{array}$} \\
\hline Hypotheses & Features Needed in Media Tools \\
\hline Acquisition & $\begin{array}{l}\text { - Synchronous methods to provide a } \\
\text { platform for natural communications } \\
\text { for L2 acquisition }\end{array}$ \\
\hline Learning & $\begin{array}{l}\text { - Asynchronous methods with rich, } \\
\text { hypermedia materials to facilitate } \\
\text { students' L2 learning }\end{array}$ \\
\hline Monitor & $\begin{array}{l}\text { - Asynchronous methods that provide } \\
\text { automated language editing functions } \\
\text { to monitor students exercise and } \\
\text { provide suggested corrections to them }\end{array}$ \\
\hline Natural Order & $\begin{array}{l}\text { - Synchronous methods to provide } \\
\text { platforms for natural communications } \\
\text { for L2 acquisition } \\
\text { - Asynchronous systems that provide a } \\
\text { structure compatible to natural order } \\
\text { for L2 learning }\end{array}$ \\
\hline Input & $\begin{array}{l}\text { - Synchronous methods to provide } \\
\text { platforms for natural communications } \\
\text { to facilitate L2 acquisition } \\
\text { - Asynchronous methods with automatic } \\
\text { selection of ' } \mathrm{i}+1 \text { ' questions and } \\
\text { exercises for L2 learning }\end{array}$ \\
\hline Affective Filter & $\begin{array}{l}\text { - Asynchronous methods to allow } \\
\text { individuals work at their own pace } \\
\text { - System should focus on providing } \\
\text { positive feed back to learners }\end{array}$ \\
\hline
\end{tabular}

Both synchronous and asynchronous media the instruction process to be automated in order to reduce the costs associated with face-to-face classroom teaching [19]. With the advances in technology, both media approaches allow a high level of information richness with sophisticated functionality for 
information retrieval. However, the two major approaches of computer mediating language instruction present noticeable differences in terms of media richness and interactivity. Instructors and course planners should take in consideration the very unique characteristics of the two approaches when they are designing and planning an instruction curriculum. Krashen's theories of second language acquisition provides us with a set of useful guidelines, which can inform us on when to use a specific kind of computer mediate tool for delivering language instruction. For example, the acquisition component in the acquisition and learning hypothesis calls for an environment in which the learners can acquire their second language competency through interaction. Asynchronous media methods, while being able to carry very rich multimedia information, lack the interactivity required for effective acquisition. Synchronous methods equipped with either audio only, or video conferencing capability can provide a platform for natural communications for second language acquisition. The learning component in the first hypothesis emphasizes conveying knowledge about the target knowledge to the learners to supplement their acquisition of the language. Asynchronous methods with rich, hypermedia materials can effectively facilitate in terms of providing a central repository for information storage and a functionality to enable the information retrieval and use by the learners.

Although learners may reduce their stresses and enhance their self-instruction and self-confidence through game and communicative activities, learners at different levels may have different behaviors and attitudes while taking a language learning course. For example, lower level learners tend to choose focusing only on audio and textual options, and high level learners, on the other hand, preferred audio practice [20]. Therefore, it is necessary for instructors to monitor students' responses carefully to ensure a structure that fits the behavioral patterns of the learner group is embedded in the selected media methods. Furthermore, instructors may not monitor learners' behaviors in an open manner as learners may develop an unnatural, 'being watched' feelings.

\section{CHALLENGE IN APPYING COMPUTER MEDIATED METHODS}

There are certain challenges in shifting the teaching of a second language from the traditional high contact environment to a computer mediated environment. These challenges come from (a) an insufficiency of technological infrastructure, (b) mixed levels of individuals' technical sophistication in using computer-enabled technologies, and (c) a need to understand and respect cultural differences.

The implementation of many of the synchronous and asynchronous media methods in language instruction requires a stringent investment in information technological infrastructure. Such infrastructure includes more modern computer hardware with sufficient memory size, expensive and complex supporting software, and the availability of a high bandwidth communication channel. The high cost associated to the provision of a sufficient level of infrastructure can be the most immediate impact on the educational system [3, 19]. Many schools just do not have the budget available for the necessary state-of-the-art hardware and software. For example, some software requires the latest programming advances, but school computers may not have the necessary components to enable these advances to be used. In addition, some school computer systems may have less than ideal memory size or speed for processing. Lai [19] points out that learners and instructors can become frustrated waiting for slow computers to download large graphics or significant amounts of data using a narrow bandwidth (e.g. dial-up service) connection to access the Internet.

Therefore, instructors must identify ways to incorporate the media effectively based not only on the needs of the students, but also within the perimeter of the educational system/environment [3]. Equally important is language instructors' technical training must be kept up, so that they are able to identify viable solutions that fit their situations $[1,21]$.

Another challenge faced by instructors is the mixed levels of the learners' computer literacy. This problem becomes particularly acute when the language instruction support systems require more mastery of the complex functionality. Both the instructors and learners may then feel an increased amount of pressure [5]. Instructors have to consider how to apply the media technology in an equitable manner so that each learner is given a fair amount of attention and care while his/her individual learning needs are also fulfilled. For example, if one learner's listening skills are not as advanced as his/her classmates, instructor may feel the need to speak more slowly during the video conferencing session. But then the more advanced classmates may not be amenable to such accommodations. Thus, the lower-level learner may require some additional assistance outside the classroom if the learners cannot be stratified in a more refined sense.

If synchronous or asynchronous media are not applied in an equitable manner, negative interactions may 
result [10]. In particular, when language learners come from different culture backgrounds, discussion topics have to be chosen carefully for online chat rooms or when posting messages. In addition, as discussed earlier, technology skills (or lack thereof) will affect learners' interactions; thus, instructors have to address learners' technological issues. Instructors also have to be trained before taking up the course [26]. An effective language course must incorporate significant interactions between learners and instructors, whether those interactions occur face-to-face in traditional courses or in the online learning environment.

\section{CONCLUSION}

This paper has discussed how synchronous and asynchronous media have been applied in the field of second language. This paper discusses both the advantages and challenges of applying the various media methods, both synchronous and asynchronous, in teaching second languages. Krashen's second language acquisition theory [9] is introduced to provide guidance in choosing the right computer mediate method in teaching second languages.

Researchers are still divided on the actual benefits of using synchronous and asynchronous media in language learning; some believe that the benefits are obvious while others weigh the potential benefits against the potential pitfalls (e.g., lack of technological skills on the part of the learners and instructors). However, most researchers agree that, as long as the instructors apply the appropriate computer instruction in their classes and support students in utilizing the tools appropriately, a positive relationship will develop between students and teachers [1, 15, 16, 27]. However, since many software applications do not support in-depth learning and are designed for profit rather than helping learners, instructors must become fluent and critical users of technology in order to choose software applications that suit learners' needs and provide relevant education $[1,21]$. The problem arises in that most certified ESL instructors have no training on how to incorporate new technology into their courses; some are not even familiar with most basic computer tools. Although recent and future students who seek ESL degree are being required to take computer courses, they are still unfamiliar with software and technologies suited for their future ESL learners [2]. Therefore, before applying any media methods in language courses, instructors and administrators have to consider the learners' needs in conjunction with the teaching and learning approaches while avoiding bad software in the field since, when bad software is used, poor learning can result.

\section{REFERENCE}

1. Hughes, J. (2005). The role of teacher knowledge and learning experiences in forming technology-integrated pedagogy. Journal of Technology and Teacher Education, 13(2), 277+.

2. Lacina, J. (2004). Promoting language acquisitions: Technology and English language learners. Childhood Education, 81(2), 113+

3. Wang, L. (2005). The advantages of using technology in second language education: Technology integration in foreign language teaching demonstrates the shift from a behavioral to a constructivist learning approach. T.H.E. Journal, 32(10), 38+

4. Hampel, R. (2006). Rethinking task design for the digital age: A framework for language teaching and learning in a synchronous online environment. ReCALL, 18(1), 105-121

5. Wang, Y. (2006) Negotiation of meaning in desktop videoconferencing-supported distance language learning. ReCALL, 18(1), 122-146

6. Hiltz, S.R., \& Goldman, R. (2005). Learning together online: Research on asynchronous learning networks. Mahwah, NJ: Lawrence Erlbaum Associates

7. Simpson, N. (2006) Asynchronous access to conventional course delivery: a pilot project. British Journal of Educational Technology 37 (4), 527-537.

8. Pelowski, S., Frissell, L., Cabral, K. \& Yu, T. (2005). So far but yet so close: Student chat room immediacy, learning, and performance in an online course. Journal of Interactive Learning Research, 16(4), 395+

9. Krashen, S. D. (1987) Principles and Practice in Second Language Acquisition. Prentice-Hall International.

10. Jepson, K. (2005). Conversations and negotiated interaction in text and voice chat rooms. Language Learning \& Technology, 9(3), 79-98.

11. Ware, P. (2004). Confidence and competition online: ESL student perspectives on Web-based discussions in the classroom. Computers and Composition, 21, 451-468.

12. Shin, D. (2006). ESL students' computer-mediated communication practices: Context configuration. Language Learning \& Technology, 10(3), 65-84

13. MacDonald, J. (2006). Blended learning and online tutoring: A good practice guide. Ashgate Publishing.

14. Pan, C. \& Sullivan, M. (2005). Promoting synchronous interaction in an eLearning 
environment: Cyber-instructors continually seek instructional tools that will hold students' attention and make online communications more efficient and effective. Skype is the latest one to test. T.H.E. Journal, 33(2), 27+.

15. Jiang, W., \& Ramsay, G. (2005). Rapport-building through CALL in teaching Chinese as a foreign language: An exploratory study. Language Learning \& Technology, 9(2), 47+.

16. Arnold, N., \& Ducate, L. (2006). Future foreign language teachers' social and cognitive collaboration online environment. Language Learning \& Technology, 10(1), 42-66.

17. Zeiss, E. \& Isabelli-García, C. (2005). The role of asynchronous computer mediated communication on enhancing cultural awareness. Taylor \& Francis Group, 18(3), 151-169.

18. Laghos, A., \& Zaphiris, P. (2005). Computer assisted/aided language learning. In C. Howard, J. V. Boettcher, L. Justice, K. Schenk, P. Rogers, \& G. A. Berg (Eds.), Encyclopedia of Distance Learning (Vol. 1, pp. 331-336). Hershey, PA: Idea Group Reference

19. Lai, C. (2006). The advantages and disadvantages of computer technology in second language acquisition. National Journal for Publishing and Mentoring Doctoral Student Research, 3(1), 1-6.

20. Hegelheimer, V., \& Tower, D. (2004). Using CALL in the classroom: Analyzing student interactions in an authentic classroom. Elsevier Ltd., 32, 185-205.

21. Susser, B. (2005). CALL and JFL teacher education in Japan: A course description. The JALT CALL Journal, 1(3), 3-16

22. Peregoy, S., \& Boyle, O. (2004). Reading, writing and learning in ESL: A resource book for K-12 teachers (4th ed.). Boston, MA: Allyn \& Bacon.

23. Warner, C. (2004). It's just a game, right? Types of play in foreign language CMC. Language Learning \& Technology, 8(2), 69-87

24. Liaw, M. (2006). E-learning and the Development of Intercultural Competence. Language Learning \& Technology, 10(3), 49-64

25. Zha, S., Kelly, P., Park, M., \& Fitzgerald, G., (2006). An investigation of communicative competence of ESL students using electronic discussion boards. Journal of Research on Computing in Education, 38(3), 349-367.

26. Hampel, R., \& Hauck, M. (2004). Towards an affective use of audio conferencing in distance language courses. Language Learning \& Technology, 8(1), 66-82

27. Lo, J., Wang, H., \& Yeh, S. (2004). Effects of confidence scores and remedial instruction on prepositions learning in adaptive hypermedia. Computers \& Education, 42(1), 45-63

28. Warschauer, M. (1998). Electronic literacies: Language, culture, and power in online education. Hillsdale, NJ: Lawrence Erlbaum Associates.

29. Wu, D. \& Hiltz, S. R. (2004) Predicting Learning from Asynchronous Online Discussions. Journal of Asynchronous Learning Networks. 8(2) 139-152.

30. Harasim, L.M. (1990) Online Education: An Environment for Collaboration and Intellectual Amplification. In Harasim, L. M. (Ed). Online Education: Perspectives on a New Environment, 39-64. NY: Praeger Publishing.

31. Krashen, S. D. (1988) Second Language Acquisition and Second Language Learning. Prentice-Hall International.

32. Krashen, S.D. (1994). Bilingual education and second language acquisition theory. In bilingual Education Office (ed.) Schooling and language-minority students: A theoretical framework (2nd ed., pp. 47-75). Los Angeles: Evaluation Dissemination and Assessment Center, California State University. 